\title{
Mensajerías SMS premium
}

\author{
Por Ángel Navarro
}

Resumen: Existe multitud de servicios a los que se puede acceder desde un teléfono móvil mediante el envío de un mensaje corto sobretarificado o SMS premium (SMS es en inglés el acrónimo de short message service). El objetivo de este artículo es describir qué hay detrás de cada uno de estos servicios, y cómo funciona su tecnología. Es importante señalar que la legislación que regula todo lo relacionado con el funcionamiento de los servicios SMS premium está actualmente en pleno proceso de re-

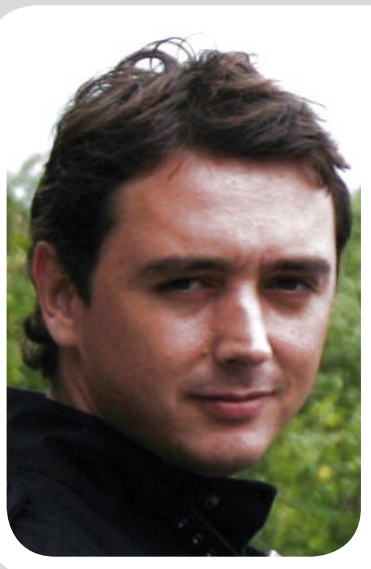

Ángel Navarro, ingeniero técnico en informática, especialidad gestión, y licenciado en documentación por la Universidad Politécnica de Valencia, es director de proyectos en la unidad B2B para Europa y Latinoamérica en Alvento Soluciones SA, sede de la multinacional de contenidos para móvil ZED Worldwide, en Valencia. Trabaja en la definición de especificaciones de proyectos de mensajería móvily ha participado en los desarrollos más importantes de España y Latinoamérica, en cuanto a cantidad de mensajes cursados, para diferentes operadoras móviles. En 2005 trabajó en Brightcontent LLC en Miami, Florida, EUA, una joint-venture entre Alvento y Brightstar Corporation, para impulsar los servicios de mensajería en Latinoamérica. Empezó su carrera profesional como documentalista en MASmedios, donde trabajó 2 años tras obtener el premio extraordinario al mejor proyecto fin de carrera de su promoción, realizado en dicha empresa. modelación en España; la información que aparece en este artículo sobre tarifas y funcionamiento básico puede verse afectada tras la entrada en vigor del nuevo plan.

Palabras clave: SMS, SMS premium, Aplicaciones y servicios de mensajería móvil, Teléfonos móviles, Texto, Contenidos de texto, Multimedia, Multimedia para móviles

\section{Title: SMS premium messaging platforms}

Abstract: There are a lot of services that can be accessed using a mobile phone by sending a premium short message (SMS premium). This article describes how the technology behind these contents and multimedia services works. The legislation about these services in Spain is currently being reviewed; the information about costs and basic functionality can be changed with the start up of the new law.

Keywords:_SMS, SMS premium, Mobile services and applications, Mobile devices, Text, Mobile text and multimedia contents, Multimedia, Multimedia for mobile devices

Navarro, Ángel. "Mensajerías SMS premium”. El profesional de la información, 2009, marzo-abril, v. 18, n. 2, pp. 223228.

DOI: 10.3145/epi.2009.mar.13

\section{Introducción}

MUCHOS HEMOS VISTO en TV, prensa $o$ internet anuncios relacionados con el envío de mensajes cortos.

Existe multitud de servicios a los que se puede acceder desde un teléfono móvil mediante el envío de un mensaje corto sobretarificado o SMS premium (SMS es en inglés el acrónimo de short message service). En este artículo se describe qué hay detrás de cada uno de estos servicios, y cómo funcionan.

Es importante señalar que la legislación que regula todo lo relacionado con el funcionamiento de los servicios SMS premium está en pleno proceso de remodelación en
España, por lo que la información que aparece en este artículo sobre tarifas y el funcionamiento básico puede verse afectada tras la entrada en vigor del nuevo plan.

\section{Servicios SMS premium}

Son los compuestos por un mensaje enviado por un usuario (MO, por sus siglas en inglés message originated) y al menos por una respuesta a ese mensaje (MT, message terminated). Por lo general, estos servicios tienen un coste superior (de ahí su nombre premium o sobretarifado) al estándar de envío de un SMS a otro usuario.

En España existen 2 tipos: por demanda y por suscripción. Los primeros son aquellos en los que el usuario envía un mensaje, y recibe una única respuesta. Las tarifas utilizadas para estos servicios son $0,15 €, 0,30 €, 0,60 €, 0,90 €, 1,20 € \mathrm{y}$ $1,50 €$ (precios sin IVA). Estos costes son los que se aplican al usuario por cada mensaje enviado a un servicio SMS premium por demanda.

En los servicios SMS premium por suscripción el usuario decide cuándo se da de alta, mediante el envío de la palabra ALTA a un número corto o bien mediante una suscripción por internet. A partir de este momento empieza a recibir mensajes del servicio, y cada uno que reciba tendrá un coste de $0,20 €$ ó $0,30 €$ (precios sin IVA). Las operadoras ponen límites para que un usuario no pueda recibir más de 
una cantidad de mensajes al día o al mes, para evitar así consumos elevados. Para cancelar la suscripción en cualquier momento, basta con enviar la palabra BAJA al mismo número que se ha enviado la palabra ALTA.

Por último, cabe señalar respecto a los costes, que los mensajes enviados a un mismo número corto siempre tienen el mismo coste, independientemente de la operadora del usuario, o del tipo de servicio. Por este motivo es común que para acceder a un servicio más caro haya que enviar varios mensajes, en el caso de servicios por demanda. En el caso de los servicios por suscripción, lo que varía es la cantidad de mensajes recibidos, ya que el usuario paga los mensajes que recibe durante el periodo que la suscripción permanece activa.

\section{Solicitud y entrega de un servicio SMS premium}

Para que todo esto sea posible se necesitan al menos 3 elementos: la operadora de telefonía, el proveedor del servicio y por supuesto, nuestro teléfono.

La operadora de telefonía es la que hace que desde el teléfono se pueda enviar un mensaje corto, que se dirige a un número también denominado corto porque su longitud es de 3 ó 4 dígitos según la legislación actual (dentro de pocos meses todos los números serán de 5 ó 6 dígitos y se podrá saber qué tipo de servicio está relacionado con cada número corto según las 2 primeras cifras de su prefijo). Pero centrándonos en la vigente legislación actual, todo empieza con una frase tipo: Envía [un texto] al número [un número corto]..., ¿qué pasa inmediatamente después de enviar ese texto a ese número corto? El mensaje y su destinatario van al centro de mensajes cortos de la operadora, ésta busca el destinatario en la red, y cuando lo localiza, envía el texto a su teléfono.
Del mismo modo, cuando se envía un mensaje a un número corto (MO), llega al centro de mensajes de la operadora móvil. En este momento, en lugar de buscar el destinatario en la red, lo que hace la operadora es identificar a la empresa propietaria del número corto y enviarle ese mensaje por internet a través de una conexión entre la operadora y la empresa.

La conexión habitualmente va a través de una VPN (virtual private network o red privada virtual, que se crea entre la operadora y la empresa proveedora del servicio) y utiliza el protocolo SMPP (acrónimo de short message peer-to-peer protocol), que es un protocolo de comunicación diseñado exclusivamente para el intercambio de mensajes cortos. En la práctica, es como si existiera un cable físico entre el centro de mensajes de la operadora y el servidor de la empresa proveedora del servicio SMS.

Cuando el mensaje llega a la empresa que debe gestionarlo, analizan el texto enviado por el usuario, determinan qué servicio ha solicitado y generan una respuesta a ese mensaje (MT). Se manda al centro de mensajes de la operadora a través de la misma conexión utilizada para recibir el mensaje enviado por el usuario. Para terminar el ciclo, la operadora busca el teléfono en la red y entrega el mensaje de respuesta que ha generado la empresa proveedora del servicio SMS.

\section{Tipos de servicios SMS premium}

Se clasifican por el tipo de función o de contenido que solicita, realiza o recibe el usuario. Pueden ser mensajes de texto o de descarga de multimedia.

De los basados en mensajes de texto existen muchas clases. Veamos algunos ejemplos:

- Votaciones: muy común en los programas de $\mathrm{TV}$, los usuarios envían un mensaje para seleccionar un ganador o un perdedor y reciben un mensaje de respuesta agradeciendo el voto.

- Envíos de opinión: también muy utilizados en programas de televisión, los usuarios envían un mensaje y tras una supervisión humana, si el contenido es apropiado se publica habitualmente en faldones situados en la parte inferior de la pantalla. Una variante de estos servicios se utilizan también en la radio para solicitar canciones, realizar dedicatorias o envíos de opinión.

- Promociones o sorteos: mediante el envío de un mensaje el usuario puede ganar un premio en ese mismo instante, o bien pasar a formar parte de una base de datos que se utiliza al finalizar la promoción para realizar sorteos de regalos. Se dan muchas variantes de este tipo de promociones: en ocasiones el usuario tan sólo tiene que enviar un mensaje, y otras veces es necesario que el usuario compre un producto y envíe un código promocional que está impreso en la etiqueta del producto comprado. En función del tipo de promoción, el usuario recibirá una respuesta confirmando si ha ganado o no un premio, o bien emplazándolo al sorteo final.

- Micropagos: los usuarios utilizan el móvil como medio de pago para acceder a un contenido o a un producto de bajo coste. Tras enviar el mensaje obtienen un código único en el mensaje de respuesta que se usa posteriormente como contraseña para acceder, por ejemplo, a secciones privadas de una web, un software o cualquier producto que necesite una contraseña.

\section{Contenidos}

\subsection{Contenidos de texto}

Los servicios más demandados son los de acceso a contenidos de texto. Un mensaje de texto tiene una capacidad máxima de 160 caracte- 
res, por lo que hay que tener mucha capacidad de síntesis para elaborar contenidos atractivos por los que el usuario esté dispuesto a pagar una pequeña cantidad. Para hacernos una idea de esta limitación, por poner un ejemplo conocido por todos, la famosa primera frase de El Quijote ya ocupa 177 caracteres, y por lo tanto no podría entregarse en un solo mensaje de texto:

En un lugar de la Mancha, de cuyo nombre no quiero acordarme, no ha mucho tiempo que vivía un hidalgo de los de lanza en astillero, adarga antigua, rocín flaco y galgo corredor.

En un mensaje de texto sólo nos cabría la parte de la frase marcada en negrita y tendríamos que prescindir del "galgo corredor".

A estas alturas probablemente el lector se estará preguntando si realmente existen textos de menos de 160 caracteres por los que un usuario esté dispuesto a pagar el mismo precio que por ejemplo tiene un diario en papel de 70 páginas. $\mathrm{O}$ quizá se esté preguntando si existen usuarios dispuestos a pagar más de 1 euro por el contenido de un texto de un par de líneas. La respuesta a ambas preguntas es SÍ, desde luego que sí.

Los tipos de contenidos por los que más se interesan los usuarios son:

- chistes,

- horóscopos, y sobre todo

- noticias o al menos titulares de noticias.

Evidentemente existen muchas otras categorías, aunque en una proporción muy reducida respecto a las mencionadas. Por poner algún ejemplo: frases de autoayuda para dejar de fumar o perder peso, consejos y trucos de cualquier tema, hasta incluso posturas del Kamasutra encajadas en ese espacio de 160 caracteres.

\subsubsection{Distribución de contenidos de texto}

Todos los contenidos que se distribuyen por SMS se encuentran normalmente alojados en bases de datos relacionales. Las personas encargadas de alimentarlas tienen un perfil profesional cercano al documentalista o periodista. Como para cualquier tipo de información, existen varias fuentes donde obtenerla.

\section{Fuentes}

El primer paso es localizar la información, asegurarse que la empresa tiene licencia para distribuirla, y después formatearla para que tenga sentido en un par de líneas. ¿Y cómo conseguir contenidos con licencia para ser distribuidos por SMS? Habitualmente las empresas proveedoras de servicios SMS tienen acuerdos con agencias de noticias tipo EFE o Atlas, y se nutren de los mismos materiales que estas agencias distribuyen a otros medios informativos. Es muy común además que las propias agencias distribuyan los contenidos ya formateados y listos para ser entregados en un mensaje. Los documentalistas y/o periodistas cuya formación incluye capacidades de síntesis de información están habituados a realizar varias versiones de un mismo texto, y ponerlo así a disposición de una publicación en papel, una publicación en internet, una lista de distribución por correo electrónico, y por supuesto una versión de 160 caracteres lista para ser consumida.

Las empresas que se alimentan de estas fuentes de información destinan una pequeña parte del precio que paga el usuario por el contenido de texto servido en un SMS, a pagar la licencia de distribución al productor de la información.

Estas empresas también recurren a internet para recopilar contenidos gratuitos o sin licencia de distribución, para incorporarlos a las bases de datos.

\section{Formateo y categorización del contenido}

Una vez conseguido un material, el siguiente paso es formatearlo -si es necesario- y categorizarlo para incorporarlo a la base de datos.

Como se ha dicho, el formateo consiste en sintetizar el contenido para que 160 caracteres sean suficientes para transmitir la información deseada.

Una primera categorización depende de la aleatoriedad o no de la información, es decir, si el usuario ha realizado una petición refinada (horóscopo del signo escorpio del próximo lunes), o más aleatoria y general (un chiste de médicos). En función del contenido pasará a formar parte de simplemente una categoría de chistes con subcategoría médicos, o habrá que almacenarlo dentro de Astrología $>$ Signos del Zodíaco $>$ Escorpio $>$ Predicción por fecha $>$ [fecha].

Para realizar esta categorización se utiliza un gestor de contenidos, herramienta que permite alimentar las bases de datos, categorizar y realizar el mantenimiento (altas, modificaciones y bajas de registros). Cuando el contenido está categorizado, se finaliza el proceso de subida y pasa a estar disponible para su entrega por SMS.

Cabe señalar que los gestores también pueden alimentarse automáticamente utilizando fuentes RSS. Básicamente se trata de materiales que preparan las agencias de noticias o proveedores y se distribuyen utilizando el formato XML. El gestor de contenidos lee las fuentes RSS periódicamente y alimenta automáticamente la base de datos ya que la categorización viene también especificada en el propio fichero XML.

Esos gestores también incorporan módulos de estadísticas que permiten realizar un seguimiento 
de peticiones de tal manera que es posible averiguar qué contenido es el más demandado por los usuarios, qué subcategorías funcionan y cuáles no, que contenidos hay que sustituir; en definitiva, datos que permiten al gestor tomar decisiones para una óptima alimentación de la base de datos.

\subsection{Contenidos multimedia}

Pueden ser: logos, tonos monofónicos, tonos polifónicos, sonidos reales, imágenes, vídeos, aplicaciones y juegos.

\subsubsection{Distribución de contenidos multimedia}

Los multimedia se guardan también en bases de datos relacionales, del mismo modo que los textos, aunque existe una diferencia importante. Éstos se guardan íntegramente en las bases de datos, en un campo dentro de una tabla que contiene un texto de 160 caracteres, ya sea una noticia de actualidad que acaba de suceder, o bien un refrán del siglo pasado. En cambio, los contenidos multimedia sólo almacenan en base de datos los metadatos asociados a cada contenido, y el contenido físico que es el que finalmente se envía al usuario se almacena en los discos duros de los servidores de la empresa que provee el contenido. Como veremos más adelante, sólo los logos y los tonos monofónicos pueden almacenarse en un mensaje de texto de 160 caracteres.

\section{Metadatos y compatibilidades}

Visto que hay varios tipos de multimedia, dentro de cada uno existen distintos formatos, tamaños, versiones, duraciones, etc. En función de estas características un móvil es capaz de reproducir o no un contenido multimedia (o sea, es compatible o no con ese contenido). Es muy importante comprobar que nuestro móvil es compatible con el contenido que queremos descargar, pues si no lo es el móvil no será capaz de reproducirlo, y no existe la posibilidad de reclamar el dinero empleado en la compra. Es lo mismo que ocurre por ejemplo si al hacer una llamada se marca un número incorrecto, hay que asumir su importe.

Los metadatos que se guardan de cada contenido multimedia dependen del tipo de contenido: formato de archivo, dimensión (bytes), duración, resolución, peso, número de polifonías y compatibilidad. La compatibilidad es la concordancia entre un tipo de contenido y una marca y modelo de móvil. Existen muchas marcas y muchos modelos de móvil distintos, e incluso versiones distintas de un mismo modelo, y estos detalles influyen en la compatibilidad del contenido con el móvil.

Por lo tanto, es necesario también mantener los metadatos de cada marca, modelo y versión de móvil. Los metadatos empleados para representar un modelo determinado son todavía más numerosos que los necesarios para definir un contenido. Algunos ejemplos son: dimensión de la pantalla, número de polifonías soportadas, tipos de archivo, tipos de imágenes, tipo de aplicaciones, tipo de melodías, resolución de la pantalla, número de colores soportados.

La tarea del personal que mantiene estas bases de datos es ardua, no sólo hay que dar de alta contenidos y modelos de móviles con todas sus características, también hay que gestionar adecuadamente las compatibilidades para asegurar que la plataforma de contenidos está actualizada y puede entregar contenidos a los móviles más modernos.

\subsubsection{Tipos de contenidos multi- media}

\section{Logos}

Estos contenidos son tan pequeños que caben en un mensaje de texto de 160 caracteres. Se envían en un SMS codificado de una manera especial que el móvil interpreta como un pequeño tablero de ajedrez, con sus casillas blancas y negras, que forman un pequeño dibujo. Se trata de un formato muy antiguo que ya prácticamente nadie consume, al menos en España, debido a la llegada de otros contenidos multimedia más sofisticados. Estos logos se colocaban antiguamente en la zona superior de las pantallas de los móviles, en el lugar destinado a mostrar el nombre de la operadora a la que pertenece el móvil.

En la figura 1 se muestra qué aspecto tiene un logo de operador. En la parte superior aparece cómo quedaría el logo en una pantalla de un móvil. La parte inferior de la imagen muestra un sencillo editor de logos:

\section{Tonos monofónicos}

Los tonos monofónicos son melodías compuestas por un solo instrumento y actualmente son los contenidos multimedia más sen-

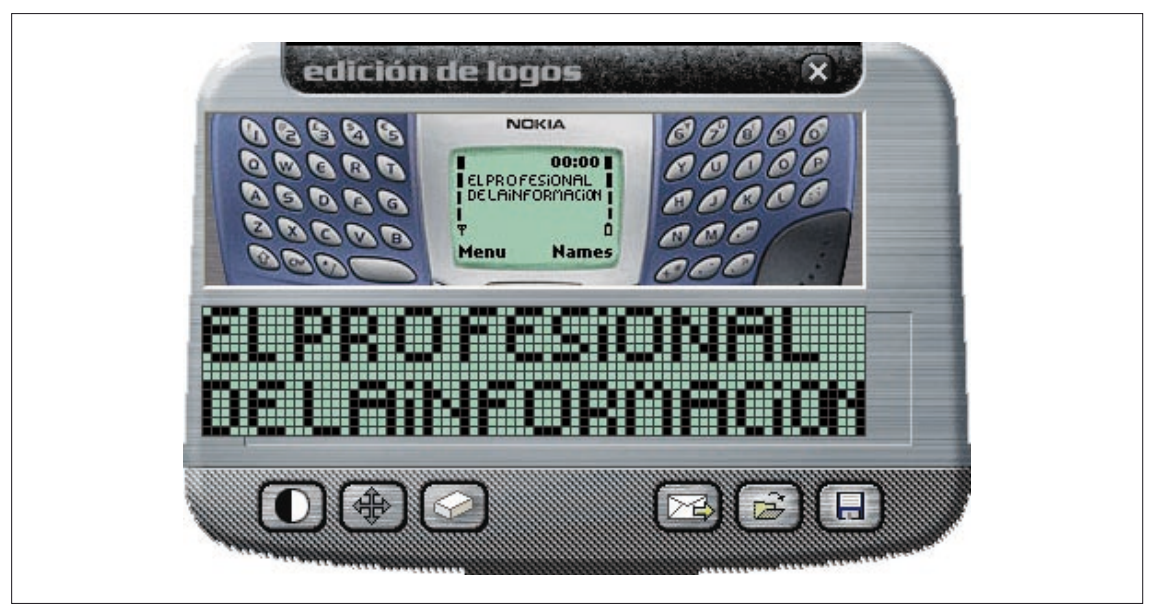

Figura 1. Editor de logos 
cillos. También caben en un solo mensaje de texto, que se envía codificado como una sucesión de notas que el móvil es capaz de interpretar y reproducir en una sola pista, es decir, sólo puede sonar una nota a la vez.

\section{Tonos polifónicos}

Son melodías más sofisticadas que los tonos monofónicos, pues como su nombre indica, están compuestos por varias tonos, habitualmente 4 ó 16 , de tal manera que pueden reproducirse todos a la vez. No pueden enviarse dentro de un mensaje de texto, ya que están formados por un tipo especial de archivo denominado Midi. Para descargarlos es necesario que el móvil se conecte a internet, por lo que lo que realmente se envía dentro del mensaje de texto no es más que un URL que el móvil interpreta como tal y permite al usuario conectar a internet para descargar el archivo de tipo Midi.

Hay que tener en cuenta que en este tipo de servicios en los que es necesario conectarse a internet para acceder a los contenidos, el usuario además asume los gastos de la conexión a internet, que dependen del tipo de contrato de cada usuario con su operadora.

\section{Sonidos reales}

Se denominan así porque reproducen cualquier tipo de sonido, voces incluidas. Hasta ahora hemos visto que tanto los tonos monofónicos como los polifónicos se limitaban a representar una melodía, dejando de lado las voces que acompañan a las canciones. Estos contenidos en cambio representan canciones completas, aunque con una calidad inferior a la que estamos habituados a escuchar en un aparato de radio o $\mathrm{TV}$, o cualquier reproductor de música. Se distribuyen habitualmente en archivos de formato amr o mp3, y es necesario también enviar una URL dentro de un mensaje de texto.

\section{Imágenes}

Conocidas como fondos de pantalla, las imágenes constituyen otro tipo de contenido multimedia distribuido por SMS. Como imagen entendemos cualquier tipo de gráfico o fotografía, que se almacena normalmente en formatos de archivo jpeg o gif. Por ejemplo, podemos utilizar el logotipo de EPI para diseñar una imagen apta para teléfonos móviles (figura 2).

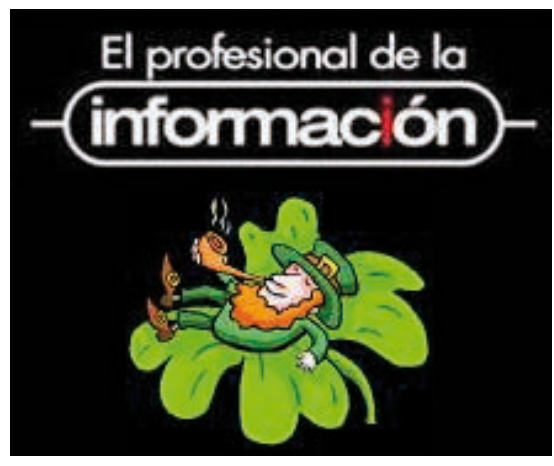

Figura 2. Ejemplo de imagen enviada a un teléfono móvil

Estos materiales también se distribuyen por SMS mediante URLs, igual que el resto de multimedia, así que es necesario que el usuario se conecte a internet para descargarlos.

\section{Vídeos}

Los vídeos son los contenidos más novedosos en el mundo de la telefonía móvil. Aunque existen desde hace tiempo, de momento no es un tipo de contenido que sea demasiado atractivo para el usuario, ya que aún resulta caro al ser el más pesado de todos. Si lo comparamos con una imagen, un vídeo de calidad y duración estándar pesa unas 10 veces más que por ejemplo la imagen que hemos utilizado como fondo de pantalla en el apartado anterior. Los vídeos se distribuyen habitualmente en archivos de tipo $3 \mathrm{GP}$, aunque cada vez son más los terminales que soportan otros tipos de formato de vídeo digital, como los que se pueden reproducir normalmente en cualquier ordenador.

\section{Aplicaciones y juegos}

Las aplicaciones para móvil son programas preparados para ejecutarse en teléfonos móviles, la mayoría de los cuales son juegos. Cada vez son más populares debido a que los móviles están más capacitados tecnológicamente para ejecutarlos y hacerlos atractivos y ‘jugables' para el usuario. Las mismas grandes empresas que distribuyen juegos para PC y consolas se encargan de distribuir las licencias de sus juegos para que los proveedores de contenido puedan crear adaptaciones de estos juegos para móvil y venderlos.

\subsection{Proceso de compra y entrega del contenido} llo:

El proceso de compra es senci-

- El usuario envía un mensaje para descargar un contenido. Ej.: Juego1.

- La plataforma busca el contenido asociado a la referencia Juego1 y lo entrega al usuario.

- El usuario intenta descargar el contenido Juego1.

- En el proceso de descarga, la plataforma de contenidos obtiene información de la marca, modelo y versión del móvil que está intentando descargar el contenido.

- La plataforma comprueba que el móvil del usuario es compatible con el contenido solicitado.

- Si es compatible, el proceso de descarga continúa hasta que la transacción se completa y el móvil descarga el contenido completo.

- Si el móvil no es compatible con el contenido, el proceso de descarga se cancela y el usuario obtiene un mensaje informativo del error.

\subsection{Modelo de negocio}

Como comentábamos al principio del artículo, cada mensaje enviado a un mismo número corto tiene un coste fijo, cuyo importe se 


\section{Bibliotecas Virtuales}

desde la digifalización de materiales bibliográficos

hasta la asignación de metradatos y su implementación

en la red, conforme a la normativa internacional

\section{Productos para crear Bibliotecas Digitales y Virtuales}

\section{DICIBIB 5.0}

Solución avanzada para la creación de Bibliotecas Digitales y la Gestión Bibliotecaria Multilingüe

DICIARCH 1.6 Sistema digital de descripción y gestión archivística

Digitalización avernzade Con asignación dinámica de metadatos
OAsls-PMH 2.0

Sistema integrado de recolección de diversos esquemas de metadatos:

DCMI sin cualificar MARC 21

EAD

mod_OAl

Implementación de las directrices DRIVER

\section{chares

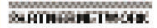

Recolección en la Web para Entidades e Instituciones de Memoria en OAI-PMH y Dublin Core e intercambio de metadatos en METS (diferentes Profiles)

Consultoría y mappings a DCMI para implementación en repositorios OAl v2.0

Tecnologías abiertas para la creación, recuperación y recolección de metadatos (MARCXML, DCMI y RDF)

Repositorios Institucionales para Preservación Digital a largo plazo mediante PREMIS y OAIS ISO 14721

- Reconocimiento Óptico de Caracteres OCR y generación dinámica de METS/Alio

- Servidor adicional de SRU Search/Retrieval via URL SRU

- Agregadores de contenido RSS DI

Validación en el Data Providers de la Open Archives Intiative. Genera un Sitemap para Google.

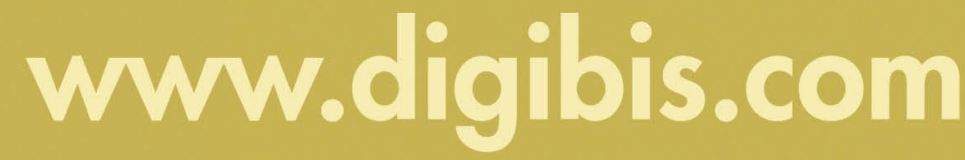

reparte entre las empresas responsables del servicio SMS aproximadamente así:

- El 50\% es para la operadora a la que pertenece el usuario.

- El 50\% restante es para el proveedor del servicio SMS. Con este $50 \%$, el proveedor del servicio tiene que liquidar a los proveedores de contenido (de texto y multimedia). Cada contenido tiene un coste distinto en función del valor añadido de ese contenido: exclusividad, calidad y originalidad son las características más diferenciadoras y por lo tanto las más caras.

\section{Servicios relacionados con Biblioteconomía y Documentación}

Una vez que hemos repasado los tipos de contenidos que pueden ser distribuidos por SMS, veamos qué servicios podrían ser interesantes para entidades relacionadas con biblioteconomía y documentación.

Algunos ejemplos podrían ser:

- Búsqueda de una publicación por ISBN / ISSN: el usuario envía un mensaje con el ISBN o ISSN deseado y obtiene la información de la publicación.

- Acceso a contenidos de pago publicados en la web EPI: el usuario descarga un artículo y envía un SMS para obtener una clave que le permite abrirlo. Está pensado para pagos de poca cantidad.

- Suscripciones de noticias relacionadas con el sector: cambios en normativas, convocatorias, ofertas de trabajo, becas, mesas redondas, etc. El usuario se suscribe a este canal de noticias y recibe las alertas de interés en su móvil, asumiendo un pequeño coste por cada mensaje recibido.

- Consulta de los indicadores de calidad de una publicación.

- Cualquier tipo de promoción o sorteo.

\section{Referencias}

Se puede ampliar la información sobre algunos conceptos tratados en este artículo en Wikipedia:

VPN o red privada virtual entre 2 entidades http://es.wikipedia.org/wiki/Red_privada_ virtual

Protocolo SMPP para la comunicación con las operadoras

http://es.wikipedia.org/wiki/SMPP

Fuentes de información RSS para la automatización de la carga de contenidos

http://es.wikipedia.org/wiki/Rss

Formato XML para representar y categorizar la información

http://es.wikipedia.org/wiki/XML

Ángel Navarro, Alvento Soluciones

SA, ZED Worldwide

angel@alvento.com

vtenaal@inf.upv.es 